\title{
A Comparison of the Relationship between Gynecological Age with Birth Weight and Chronological Age with Birth Weight in Teenage Mothers in Kota Bekasi West Java
}

\author{
Siti Masyitah ${ }^{1, *}$, Kusharisupeni $^{2}$ \\ ${ }^{1}$ Post Graduate Program in Public Health Studies, University of Respati Indonesia, Indonesia \\ ${ }^{2}$ Department of Nutrition in Public Health Faculty, University of Indonesia, Indonesia
}

Copyright $\mathrm{C} 2018$ by authors, all rights reserved. Authors agree that this article remains permanently open access under the terms of the Creative Commons Attribution License 4.0 International License

\begin{abstract}
Background: Teenage pregnancy is high-risk pregnancies are associated with a high incidence of premature birth, low birth weight (LBW), and other adverse pregnancy outcomes. Aim: We examined the relationship between gynecological age and birth weight and chronological age with birth weight in teenage mothers in eight, Puskesmas Kota Bekasi. We determined differences in the strength of the relationship between gynecological age and chronological age with birth weight in teenage mothers in Bekasi. Research methods: This is a cross-sectional study to investigate the correlation between gynecological age and chronological age as an independent variable, with birth weight as the dependent variable. Result: Mothers with gynecological age $<4$ years than their chronological age had a 4 fold risk of having a baby weighing $<3000$ grams, which is the birth weight-related to non-communicable diseases in adulthood, and mothers with chronological age $<16$ years had a 2 times higher risk of giving birth to babies weighing $<3000$ grams. Pre-pregnancy stature, pre-pregnant BMI, the increase in weight during pregnancy and anemia were found to be confounding factors in the relationship between gynecological age and chronological age with birth weight of babies. Conclusion: Gynecological age and chronological age are associated with infant birth weight in teenage mothers in Bekasi 2015. Gynecological age is more strongly correlated with birth weight compared with chronological age. Suggestion: It is advisable to delay the first pregnancy for women in Indonesia to at least 18 years of age. Another study is done by looking at the risk of gynecological age and chronological age with low birth weight and stunted growth.
\end{abstract}

Keywords Gynecological Age, Chronological Age, Teenage Pregnancy, Birth Weight

\section{Background}

Teenage pregnancy is a high-risk pregnancy. It is associated with a high incidence of premature birth, low birth weight (LBW), and other adverse pregnancy outcomes [1]. Young women are shorter, their bodies are not fully mature and they have a lower body weight compared to older women. The babies of these young mothers are also more likely to be born premature, or be stillborn [2]. In addition to preterm birth, babies born to mothers in their teens are also at risk of having a low birth weight, ie. below 2.5 kilograms due to lack of nutrition during pregnancy, also congenital birth defects or abnormal fetal growth can be prevalent (Madya, 2010) [3]. The city of Bekasi is administratively divided into 12 Sub-districts and 56 Sub-districts. The city of Bekasi is classified as a densely populated area. Until 2014 the population of Bekasi City has reached 2,382,689 and the number of people 10-19 years in Bekasi City until 2016 is 468,740 . During the period of 6 years of population growth Bekasi City reached 23.71 percent. Younger marriage $<20$ years old that occurred in the city of Bekasi also still quite high (25.9\%) (West Java in the figures of 2012). Bekasi City Health Office mentions that until October 2014 there are 1725 pregnant women with age $<20$ years and until October 2015 there are 1634 pregnant women with age $<20$ years.

In the present study the authors intended to make a comparison of the relationship between gynecological age and chronological age to birth weight, especially in the teenage mother. We investigate whether gynecological age or chronological age is a better indicator for birth weight in teenage pregnancy. A previous study in Atlanta, USA, on the impact of early childhood during pregnancy on the health of mothers and babies, found that a low gynecological age $(\leq 2$ years since menarche) or age at conception or delivery $(\leq 16$ years) were good predictors of low birth weight (Gibbs et al, 2012) [4].

\section{Aims}

This study aims to identify and assess the relationship between gynecological age with birth weight and 
chronological age with birth weight in teenage mothers in Bekasi City and determine the differences in the strength of the relationship between these factors

\section{Method}

We included 170 teenage mothers aged $<=19$ years old from 8 public health center in Bekasi City with simple random sampling. Inclusion criteria were first pregnancy mother, at term, normal delivery. Exclusion criteria were gemeli, premature, and not Bekasi civilian. This study was a cross sectional epidemiological study to analysis the correlation between risk factors (age gynecological and chronological age) as independent variables. Gynecological age was defined as age at first pregnancy minus age at menarche, chronological age as age at first pregnancy. Birth weight was the dependent variable. Birth weight was low as identified below 3000 grams because this was the median split value. Previous studies have also identified this as a risk weight below which the risk for later life morbidity increases (Barker phenomenon) [5]. Covariates in logistic regression analyses were maternal education, and occupation, income. Health data included anthropometric data such as height before pregnancy and body mass index (BMI), the increase in weight during pregnancy, consumption of iron tablets, anemia status, and frequency of Antenatal Care (ANC) For statistical analyses mother's BMI was grouped into normal when $<16.5$ for age $<19$ years and $<18.5$ for age $>=19$ years. Normal BMI $>=16.5$ for age $<19$ years and $>=18.5$ for age $>=19$ years. Weight gain additions during pregnancy were grouped into inadequate and adequate, according to BMI for age $<19$ years (the addition of at least $12.5 \mathrm{~kg}$ pregnant with a BMI $<18.5$ ) and for age $>=19$ years (extra pregnant women's weight ranged from $11.5 \mathrm{~kg}$ with a BMI of 18.5 to 25$)$. Gynecological age was grouped according to
Warman R, 1982 [6] which is 4 years old and birth weight stratified by birth weight by Hales and Barker (2001) is 3000 grams (associated with degenerative disease). Chronological age of respondents was grouped by restrictions, 16 years [7].

\section{Results}

Most babies were born with normal weight $(>=2500$ grams), only $5 \%$ had a birth weight $<2500$ grams. A total of $42.4 \%$ of infants was born weighing $<3000 \mathrm{~g}$. Average birth weight was 3025 grams (median $/$ mode $=3000 \mathrm{~g}$, range: 2100- 3800 grams, standard deviation 362.04 grams)

\section{Maternal Health Characteristics}

Health data presented are teenage mothers whose anthropometric data included height before pregnancy and body mass index (BMI), the increase in weight during pregnancy, consumption of iron tablets, anemia status, and frequency of Antenatal Care (ANC) (see table). The average maternal height median $154.36 \mathrm{~cm}$ and $155 \mathrm{~cm}$ (for analyses mother's height was grouped into $<150 \mathrm{~cm}$, and $>=150 \mathrm{~cm}$, which comprised $11.8 \%$ of mothers). The average BMI before pregnancy was 21.77 and the median 21.75. Almost all respondents had a normal BMI. The average addition of weight gain during pregnancy was $10.98 \mathrm{~kg}$, median $11 \mathrm{~kg}$. About half (48.8\%) of women with the addition of weight gain during pregnancy is inadequate according to BMI. Most of the mothers had taken iron tablets during pregnancy. Hemoglobin $(\mathrm{Hb})$ level was based on gestational age are $11.8 \%$ who check her hemoglobin levels in the first trimester, $40 \%$ were checked his hemoglobin levels in the second trimester, and $48.2 \%$ who examined her $\mathrm{Hb}$ levels in the third trimester. A total of $37.6 \%$ of mothers suffer from anemia $(\mathrm{Hb}<11 \mathrm{~g} / \mathrm{dl})$, and there are $14.1 \%$ of mothers who do ANC $<4$ times. Results can be seen in the following table (table 1). 
Table 1. Distribution Characteristics of Maternal Health

\begin{tabular}{|c|c|c|c|c|}
\hline Variable & Mean (SD) & Median & $\mathrm{N}$ & $\%$ \\
\hline Stature & $154,36 \mathrm{~cm}( \pm 362,039)$ & $155 \mathrm{~cm}$ & - & - \\
\hline BMI & $21,77( \pm 2,96)$ & 21,75 & - & - \\
\hline Category of Stature & - & - & - & - \\
\hline$<150 \mathrm{~cm}$ & - & - & 20 & 11,8 \\
\hline$>=150 \mathrm{~cm}$ & - & - & 150 & 88,2 \\
\hline Category of BMI & - & - & - & - \\
\hline Not normal & - & - & 4 & 2,4 \\
\hline Normal & & & 164 & 97,6 \\
\hline Iron consumption & - & - & - & - \\
\hline No & & & 14 & 8,2 \\
\hline Yes & & & 156 & 91,8 \\
\hline Weight gain & $10,98 \mathrm{~kg}$ & $11 \mathrm{~kg}$ & - & - \\
\hline Not adequate & - & - & 83 & 48,8 \\
\hline Adequate & - & - & 87 & 51,2 \\
\hline Anaemia & - & - & - & - \\
\hline Yes & - & - & 64 & 37,6 \\
\hline No & - & - & 106 & 62,4 \\
\hline ANC & 7 & 7 & - & - \\
\hline$<4$ times & & & 24 & 14,1 \\
\hline$>=4$ times & & & 136 & 85,9 \\
\hline
\end{tabular}

Relationship between Gynaecological Age, Chronological Age and Characteristics of Teenage Mothers with Birth Weight

$68 \%$ of respondents had a gynecological age $<4$ years and $43 \%$ a gynecological age $>=4$ years. There was a significant difference (Chi square test $\mathrm{p}=0.002$ ) between baby birth weight and women of different gynecological age. The $\mathrm{OR}=$ 4.333 meaning that women with gynecological age $<4$ years 4.3 times the risk of having a baby weighing $<3000$ grams compared to the mother at the age of gynecological $>=4$ years.

The results of the analysis between chronological age with birth weight showed that $54 \%$ of respondents with chronological age $<16$ years gave birth to infants weighing $<3000 \mathrm{~g}($ Chi square $=\mathrm{p}=0.08(>0.05)$ means that there is no significant difference in the proportion of birth weight among respondents chronological age $<16$ years with the respondent's chronological age $>=16$ years. However, there is a tendency that the proportion of women with chronological age $<16$ years old are giving birth to babies weighing $<3000$ grams compared to mothers aged $>=16$ years.

To clarify the role of these risk factors on birth weight can be seen in the following example:

1). The age of menarche 10 years old (the youngest age of menarche in this study) in case of pregnancy with a gynecological age $<4$ years (eg. 3 years) mean pregnant women at 13 years of chronological age $(<16$ years of the minimum limit of chronological age in this study), the mother 4 times the risk of giving birth to babies weighing $<3000 \mathrm{~g}$ and 2 times the risk of death and when a pregnancy with gynecological age of 4 years (minimum in this study) means that pregnant women at the chronological age of 14 years and are still at risk.

2 ). menarche age of 14 years (the oldest menarche age in this study) in case of pregnancy with a gynecological age $<4$ years (eg. 3 years) mean pregnant women at the chronological age of 17 years and in case of pregnancy with a gynecological age 4 years mean maternal age chronologically 18 years.

3 ). The age of menarche of 11.5 years (median in this study) in case of pregnancy with a gynecological age $<4$ years (eg. 3 years) mean pregnant women at the chronological age of 14.5 years, the risk of mother four times give birth to babies weighing $<3000$ gram and in case of pregnancy with a gynecological age 4 years mean pregnant women at the chronological age of 15.5 years, the risk of second mother gave birth to babies weighing $<3000$ grams.

The results of this study indicate that the age of menarche should not be ignored because of the young age of menarche and so the higher the risk of giving birth to babies weighing $<3000$ grams making gynecological age should be $>4$ years and chronological age should be $>16$ years. 
In this research study respondents grouped by low education when less than 9 years and higher education when it is more than or equal to 9 years. The results of the analysis between education and birth weight was found in the group of respondents with lower education are $43.3 \%$ who gave birth to infants weighing $<3000 \mathrm{~g}$ and the group of respondents with higher education are $41.9 \%$ who gave birth to infants weighing $<3000 \mathrm{~g}$, the value of $\mathrm{p}=0.995(>0.05)$ means that there is no significant difference in the proportion of birth weight infants among low educated respondents with highly educated respondents. Works of respondents are grouped based on employment status (employed and unemployed). The results of the analysis work to the birth weight was found in the group of respondents with the status of work are $54.2 \%$ who gave birth to infants weighing $<3000$ $\mathrm{g}$ and the group of respondents did not work there are $40.4 \%$ who gave birth to infants weighing $<3000 \mathrm{~g}, \mathrm{p}=0.298$ ( $>$
0.05) means that there is no significant difference in the proportion of birth weight among respondents who work with the respondents that did not work.

Income of respondents is grouped based on the median income of IDR. 2.300.000, -. Low income when $<$ IDR. 2.300 .000 , high income if $>=$ IDR $2.300 .000,-$. The results of the analysis between revenue birth weight was found in the group of respondents with low incomes are $46.4 \%$ who gave birth to infants weighing $<3000$ grams and in groups of high-income respondents are $38.4 \%$ who gave birth to a baby weighing $<3000$ grams, $\mathrm{p}=0.905(>0.05)$ means that there is no significant difference in the proportion of birth weight infants among low-income respondents to the respondents who earn high. Chi-square test result can be seen in the following table:

Table 2. Relationship between Gynaecological Age, Chronological Age and Characteristics of Teen Mothers with Birth Weight

\begin{tabular}{|c|c|c|c|c|c|c|c|c|}
\hline \multirow{3}{*}{ Variable } & \multicolumn{6}{|c|}{ Birth weight } & \multirow{3}{*}{$p$ value } & \multirow{3}{*}{$\begin{array}{c}\text { OR } \\
(95 \% \text { C.I })\end{array}$} \\
\hline & \multicolumn{2}{|c|}{$<3000 \mathrm{~g}$} & \multicolumn{2}{|c|}{$>=3000 \mathrm{~g}$} & \multicolumn{2}{|c|}{ Total } & & \\
\hline & $\mathrm{n}$ & $\%$ & $\mathrm{n}$ & $\%$ & $\mathrm{n}$ & $\%$ & & \\
\hline \multicolumn{9}{|l|}{ Gynaecological age } \\
\hline$<4$ years & 18 & 72,0 & 7 & 28,0 & 25 & 100,0 & \multirow{2}{*}{0,002} & 4,33 \\
\hline$>=4$ years & 54 & 37,2 & 91 & 62,8 & 145 & 100,0 & & $(1,700-11,046)$ \\
\hline \multicolumn{9}{|l|}{ Chronological age } \\
\hline$<16$ years & 25 & 54,3 & 21 & 45,7 & 46 & 100,0 & \multirow{2}{*}{0,08} & 1,95 \\
\hline$>=16$ years & 47 & 37,9 & 77 & 62,1 & 124 & 100,0 & & $(0,984-3,866)$ \\
\hline \multicolumn{9}{|l|}{ Education } \\
\hline$<=$ middle school & 20 & 43,5 & 26 & 56,5 & 46 & 100,0 & \multirow{2}{*}{0,995} & 1,06 \\
\hline$>$ middle school & 52 & 48,4 & 72 & 51,6 & 124 & 100,0 & & $(0,538-2,110)$ \\
\hline \multicolumn{9}{|l|}{ Work status } \\
\hline Working & 13 & 54,2 & 11 & 45,8 & 24 & 100,0 & \multirow{2}{*}{0,298} & 1,74 \\
\hline Not working & 59 & 40,4 & 87 & 59,6 & 146 & 100,0 & & $(0,731-4,153)$ \\
\hline \multicolumn{9}{|l|}{ Income } \\
\hline < IDR. 2.300 .000 & 39 & 43,3 & 51 & 48,9 & 90 & 100,0 & \multirow{2}{*}{0,905} & 1,089 \\
\hline$>=$ IDR. 2.300 .000 & 33 & 41,3 & 47 & 58,7 & 80 & 100,0 & & $(0,592-2,004)$ \\
\hline
\end{tabular}

Table 3. Analysis of Relationship between Gynecological Age with Birth Weight

\begin{tabular}{|c|c|c|c|c|c|c|c|c|}
\hline & \multirow{2}{*}{} & B & S.E. & \multirow{2}{*}{ Wald } & \multirow{2}{*}{ df } & \multirow{2}{*}{ Sig. } & \multirow{2}{*}{ Exp (B) } & \multicolumn{2}{|c|}{$95 \%$ C.I. for EXP(B) } \\
\cline { 4 - 9 } & & & & & & & Lower & Upper \\
\hline Gynecological age & 1.422 & .491 & 8.403 & 1 & .004 & 4.145 & 1.585 & 10.842 \\
\hline Pregnant stature & .999 & .539 & 3.444 & 1 & .063 & 2.717 & .945 & 7.806 \\
\hline Pre-pregnancy BMI & 1.864 & 1.184 & 2.479 & 1 & .115 & 6.449 & .634 & 65.636 \\
\hline Pregnancy Weight gain & .423 & .336 & 1.584 & 1 & .208 & 1.527 & .790 & 2.950 \\
\hline Anaemia & -.482 & .351 & 1.888 & 1 & .169 & .618 & .311 & 1.228 \\
\hline Constant & -7.742 & 2.822 & 7.529 & 1 & .006 & .000 & & \\
\hline
\end{tabular}


Table 4. Analysis of Relationship between Chronological Age with Birth Weight

\begin{tabular}{|c|c|c|c|c|c|c|c|c|}
\hline & \multirow{2}{*}{ B } & \multirow{2}{*}{ S.E. } & \multirow{2}{*}{ Wald } & \multirow{2}{*}{ df } & \multirow{2}{*}{ Sig. } & \multirow{2}{*}{$\operatorname{Exp}(\mathrm{B})$} & \multicolumn{2}{|c|}{$95 \%$ C.I. for $\operatorname{EXP}(B)$} \\
\hline & & & & & & & Lower & Upper \\
\hline Chronological Age & .702 & .366 & 3.671 & 1 & .055 & 2.018 & .984 & 4.137 \\
\hline Pre-pregnant stature & .978 & .527 & 3.445 & 1 & .063 & 2.660 & .947 & 7.474 \\
\hline Pre-pregnant BMI & 1.857 & 1.188 & 2.443 & 1 & .118 & 6.408 & .624 & 65.810 \\
\hline Pregnancy weight gain & .512 & .332 & 2.370 & 1 & .124 & 1.668 & .870 & 3.200 \\
\hline Anaemia & -.497 & .344 & 2.085 & 1 & .149 & .608 & .310 & 1.194 \\
\hline Constant & -5.668 & 2.663 & 4.530 & 1 & .033 & .003 & & \\
\hline
\end{tabular}

\section{Gynecological Age and Birth Weight}

The result of multivariate analysis showed that the significant variables related to the incidence of birth weight were gynecological age with pregnant stature, pre pregnant BMI, addition of pregnant weight, and anemia as confounding variable or confounding of relationship between gynecological age with birth weight. The result of the analysis was gynecological age of 4,145 , mean that gynecologic mother $<4$ years old will give birth baby weighing $<3000$ gram equal to 4 times higher than mother with gynecological age $>=4$ years after controlled variable of pregnant stature, pre pregnant BMI, pregnancy weight gain, and anaemia (table 3).

\section{Chronological Age and Birth Weight}

The result of multivariate analysis was found that chronological age variable was related to infant birth weight, while pregnancy prenatal, pre pregnant BMI, pregnancy weight gain and anemia as confounding variable or confounding gynecological age relationship with birth weight as confounding. The chronological age $=0,055$ means that chronological age correlated with birth weight of infant with chronological age value of 2.018 , meaning that the mother with chronological age $<16$ years old will give birth baby weighing $<3000$ gram equal to 2 times higher than mother with chronological age $>=16$ years after controlled by pregnant stature, pre pregnant BMI, pregnant weight gain, and anaemia (table 4).

The end result of the two multivariate analyzes showed that the stronger variables associated with the incidence of birth weight was the gynecologic age variable based on their OR value, whereas the pregnant stature variable, pre pregnancy BMI, pregnancy weight gain, and anemia as confounding variables. The result of the analysis was gynecological age of 4,145 , mean that gynecologic mother $<4$ years old will give babies weighing $<3000$ gram 4 times higher than mothers with gynecological age $>=4$ years after controlled by pregnant stature, pre pregnant BMI, pregnancy weight gain, and anaemia. The gynecologic age variable was stronger in association with birth weight $(\mathrm{OR}=5.017)$ compared with chronological age $(\mathrm{OR}=2.237)$. Interaction tests were performed at gynecological age and chronological age with confounding variables but no interactions as none showed significant $\mathrm{p}$ value.

\section{Discussion}

This study found infants with birth weight $<2500$ grams as much as $7.6 \%$ even though all babies are born with gestational age months or at term. About one in twelve babies are born with low birth weight. Low birth weight babies are an important issue in its management because it has a tendency toward increased infection, difficulty regulating the breath of the body making it easy to suffer hypothermia. In addition, infants with LBW are susceptible to certain complications such as jaundice, hypoglycemia that can cause death. Low birth-weight infants may be terminated with high-risk groups, as in low-birth-weight babies it shows a higher rate of death and health than the birth weight ${ }^{8}$.

Increased intrauterine infant growth is also known as stunted growth, small-to-gestational age. Sometimes a mother has a full gestational age but gives birth to a baby with low birth weight. In most cases, these babies are relatively healthy, only small. Parental genetics or other factors such as the lifestyle of pregnant women, food intake, may be the reason why infants are fairly born with low birth weight. However there is a decrease in the number of cases due to good prenatal care (Kulich, 2015). ${ }^{9}$

In this study, there were three mothers $(1.8 \%)$ with 2-year gynecologic age delivering babies with birth weight $<3000$ grams. LBW occurs in some women with a gynecological age of 3 years, and as many as $72 \%$ of mothers whose gynecological age $<4$ years of birth have babies weighing $<3000$ grams. The result of chi-square test showed that there was a significant difference of proportion on baby's birth weight between gynecologic respondents $<4$ years with gynecological age $>4$ years. There is a tendency that respondents with gynecological age $<4$ years gave birth to babies with birth weight less than birth weight of this research point of 3000 grams. In this study also found more than half of mothers with gynecological age $<4$ years gave birth to babies weighing less than 3000 grams. According to Frisancho, this can occur because of low gynecological age, when associated with incomplete maternal growth, will result in reduced birth weight. This finding supports the 
hypothesis that among growing teenagers there is competition for nutrition between maternal and fetal growth needs. This competition does not occur among teenagers who have completed their growth. The results of this study are in line with Frisancho 10

Low gynecological age contributes proportionally to the risk of premature birth in this adolescent group. Scholl, 1992, mentioned that low gynecological age contributes proportionally to the risk of preterm birth and LBW in adolescent groups. Warman R, et al., in 1982, in Latin America mentions that adolescents with 3-year gynecological age are at risk of delivering babies weighing $<2500$ grams. In this study also found teenage mothers with gynecological age of 3 years gave birth to babies weighing $<2500$ grams, meaning the results of this study proves that women with gynecological age $<4$ years at risk of delivering babies weighing $<3000$ grams. The results of this study are in line with the results of research Warman $\mathrm{R}$ that adolescents with 3-year gynecological age at risk of delivering babies weighing $<2500$ grams. Gibbs, et al, 2012, mentioned that in particular, studies in low-income countries need to consider low gynecological age as exposure, not just chronological age. Gynecological age shows a greater birth weight risk $<3000$ grams compared with chronological age, because gynecological age is affected by age of menarche, while chronological age is independent of age of menarche.

In this study found the age of menarche $<=11$ years there is $52.4 \%$, age 12 years menarche there are $37.6 \%$; Menarche age 13 years and 14 years: $10 \%$. While the Riskesdas 2010 results show that $5.2 \%$ of girls experienced menarche at age $<=11$ years, $17.2 \%$ at age $12,20 \%$ at age $13,17.5 \%$ at age 14 years, $15.2 \%$ at age 15 years. This means that if we use a $<4$ year cutoff point for gynecological age at risk, then there are $22.4 \%$ of children with chronological age $<16$ years, $20 \%$ who have chronological age $16-<17$ years, $17.5 \%$ who have chronocyte ages $17-<18$ Year and $15.2 \%$ having chronological age of $18-<19$ years. Thus nearly $60 \%$ of those who become pregnant at $<18$ years of age have a risk of delivering babies with birth weight $<3000$ grams.

Among teenagers, there is wide variation in time, intensity, and duration in rapid growth. The average duration of puberty in adolescent girls is 4 years with an ionterval between 1.5 - 8 years. After the height growth is complete, the pelvic bone is still growing in a few years. The growth of the pelvis can be completed by the age of 16 until the age of 23 years. This means that pelvic growth is completed several years after height growth is completed (several years after 16 - 23 years). It is also mentioned that after menarche, height growth can still last for 4-7 years. Therefore it is recommended that the first pregnancy be delayed at least until the age of 19 years. Usually countries whose female population suffers a lot of malnutrition, the increase in height tends to be longer and can be completed in older age compared to countries whose malnutrition prevalence is lower. Means in countries where the prevalence of malnutrition is high, adolescent girls have not finished growing until older age. In countries with good nutritional status, menarche age tends to be younger and growth tends to be faster, so maybe at the age of 16 years of growth is over. Conversely, in countries where nutritional status is poor, new growth may be possible by the age of 23 .

The results of this study indicate that the effect of gynecological age is greater than the chronological age because in this study all who have gynecological age $<4$ years have chronological age $<16$ years. While chronologically $<16$ years old some have gynecological age $>$ $=4$ years. The results of this study also indicate that the age of menarche remains to be considered because the younger the menarche age the higher the risk of giving birth to babies weighing $<3000$ grams so that gynecological age should be $>$ 4 years and chronological age should be $>16$ years in order to reduce risk.

In relation to adolescent pregnancy outcomes, this study found LBW in the $<16$ years age group, this result proves that pregnancy at $<16$ years of age is at risk of delivering babies with low birth weight. Gibbs, 2012, mentions that mothers of very young age $(<15$ years of age or older, who are prone to malnutrition and menarche) have an impact on maternal growth and growth and survival. The growth of pelvic height and development is completed 2 years after menarche and is stated as low gynecological age and expressed as exposure. The biological mechanisms in very young mothers and their outcomes may differ depending on the mother or infant outcome. This study is in line with Gibbs.

In this research with logistic regression test in final model found there is correlation between chronological age with baby birth weight. Mothers with chronological age $<16$ years are twice as likely to have babies weighing $<3000$ grams compared with chronological mothers $>=16$ years. In women with chronological age $<14$ years found $50 \%$ of babies $<3000$ grams, in women aged $15-16$ years found $42.9 \%$ of babies $<3000$ grams, and in mothers aged 17-19 years found $42.9 \%$ Baby $<3000$ gram. These results are consistent with Rochjati's assertion that maternal age is closely related to birth weight where pregnancies are under 16 years are high-risk pregnancies, 2-4 times higher in comparison with pregnancies in women of old age. Despite the fact all respondents in this study were teenage mothers who are physiologically undergoing the process of growth and development. At a young age, the development of reproductive organs and physiological functions is not optimal. In addition, his emotions and psychology is not mature enough, so that during pregnancy the mother has not been able to respond to her pregnancy perfectly and often complications occur. In addition, the younger the age of pregnant women, the danger of infants born less months, bleeding will occur and the baby was born lightly.

\section{Conclusions}

Based on the results and discussion that has been 
described in this study, the conclusions are as follows:

1. Age gynecological related to birth weight where low gynecological age 4 times likely to give birth to infants weighing $<3000$ grams and there is a correlation between chronological age with low weight chronological lahir. Usia 2 times the chance of having a baby weighing $<3000$ grams.

2. Age gynecological more strongly correlated with birth weight compared with chronological age based on the OR. Age gynecological indicate the risk of birth weight $<3000 \mathrm{~g}$ larger than the chronological age, because age gynecological influenced by age of menarche, while chronological age independent of the age of menarche.

3. The findings of this study prove that a gynecological age $<4$ years had a risk four times more likely to give birth to infants weighing $<3000 \mathrm{~g}$, birth weight associated risk of non-communicable diseases in adulthood, compared with those who had a gynecological age 4 years or more. While chronological age $<16$ years have two times greater risk of having infants weighing $<3000$ grams compared to those with the chronological age of 16 years or more.

\section{Suggestions}

Based on the findings in this study may be submitted several suggestions as follows:

- Department of Health and Bekasi City Government is expected to improve and reinforce efforts to prevent teenage pregnancy so that the teens want to delay the age of marriage until well into the ideal age of marriage (20 years for women and 25 years for men).

- In cooperation with the institutions or community organizations to provide health services to adolescents dan penyuluhan on safe age for reproduction based on age and chronological age gynecological and explain bahay teen pregnancy both the mother and baby. Providing sexual education for teenagers in particular and to society in general. Provide counseling to parents who have teenage children to watch them not to give a chance to enter promiscuity.

\section{Acknowledgements}

This paper is dedicated for University of Respati Indonesia Jakarta. Thank you so much to Prof. Kusharisupeni, Prof. Sudijanto Kamso, Prof. Ratna Djuwita, Prof. Notoatmodjo, Dr. Anies Irawati, Dr. Raditya, Dr. Besral, at University of Indonesia.

\section{REFERENCES}

[1] Kayastha S1, A2 Pradhan, 2012. Department of Obstetrics and
Gynecology, Nepal Medical College Teaching Hospital. Obstetric Outcome of Teenage Pregnancy. NJOG 2012 Jul-Dec; 7 (2): 29-32.

[2] Save The Children Organization: One in Ten Babies born by Teenagers. Mei 7, 2013

[3] Madya, Fatmawati, 2010. Adolescent pregnancy has a high risk of death. Tempo, January $2^{\text {nd }} 2010$

[4] Gibbs, Cassandra M, 2012. The Impact of Early Age at First Childbirth on Maternal and Infant Health. Paediatric and Perinatal Epidemiology. Volume 26, Issue Supplement s1, pages 259-284, July 2012.

[5] Hales \& Barker, 2001. The thrifty phenotype hypothesis: Type 2 diabetes. C Nicholas Hales David J P Barker Br Med Bull (2001) 60 (1): 5-20. 2001

[6] Warman R, et al, 1982. Evaluation of pregnancy and delivery in low gynecologic age adolescents. Prog Clin Biol Res. 1982; 112 Pt B: 239-48.

[7] Scholl, Theressa, 2006. Association between low gynaecological age and preterm birth. Paediatric and Perinatal Epidemiology.

[8] Damanik, 2008. Infant Classification by Birth Weight and Gestation Period. In: Sholeh Kosim, et al. Textbook Neonatology. Jakarta: IDAI Publishing Agency, 11-30.

[9] Kulich, 2015. Low Birth Weight. http://www.pregnancycorner.com/giving-birth/complications/ low-birth-weight.html.

[10] Frisancho, A Roberto, Jorge Matos and Laura A. Bollettino. 'Role of Gynecological Age and Growth Maturity Status in Fetal Maturation and Prenatal Growth of Infants Born to Young Still-Growing Adolescent Mothers" Human Biology Vol. 56, No. 3 (September 1984), pp. 583-593

[11] Almatsier, Sunita, 2001. Basic Principles of Nutrition. Publisher PT Gramedia Jakarta.

[12] Auger, Nathalie, et al, 2013.Contribution of Maternal Age to Preterm Birth Rates in Denmark and Quebec, 1981-2008. American Journal of Public Health: October, 2013, Vol. 103, No. 10, pp. E33-e38.doi: 10.2105 / AJPH.2013.301523

[13] Beydoun, Hind, 2004. Impact of Maternal Age on Preterm Delivery and Low Birth weight: A Hospital-Based Collaborative Study of nulliparous Lebanese Women in Greater Beirut. Department of Pediatrics, the American University of Beirut Medical Center, Beirut, Lebanon

[14] Carel JC, Elie C, Ecosse E, et al. Self-esteem and social adjustment in young women with Turner syndrome-influence of pubertal management and sexuality: population-based cohort study. J Clin Endocrinol Metab 2006; 91: 2972-2979.

[15] Chen, Xi Kuan, 2006. Teenage pregnancy and adverse birth outcomes: a large population-based retrospective cohort study. 1OMNI Research Group, Department of Obstetrics \& Gynecology, University of Ottawa, Ottawa, Ontario, Canada. International Journal of Epidemiology. 2006.

[16] Coleman, Erin, 2014. Nutrition Problems for Teens. Healthy eating by Demand Media.

[17] Dunbar, Jessica, et al, 2008. Age at menarche and First Pregnancy among At-Risk Psychosocially Adolescents. 
American Journal of Public Health. 2008 October; 98 (10): $1822-1824$

[18] Elwood, J. Mark, 2007. Critical Appraisal of Epidemiological Studies and Clinical Trials. Oxford University Press.

[19] Engle WA. American Academy of Pediatrics Committee on Fetus and Newborn. Age terminology during the perinatal period. Pediatrics 2004; 114: 1362-1364

[20] Eriksson JG. Early growth and coronary heart disease from Helsinki birth cohort Study (HBCS). Am J Clin Nutr. 2011; 94: 1799S-802S.

[21] R. Fagan, 2006, in IDAI, 2013.Counseling and Treating Adolescents with Alcohol and Other 15.Substance Use Problems and their family. The Family Journal: Counseling Therapy for Couples and Families. Vol.14. No.4.326-333. [Downloadable 2014-2015 February 13, at: 20:00].

[22] Felice, Marianne E, et al, 1984. Observations Related to Chronologic and Gynecologic Age in Pregnant Adolescents. The Yale Journal Of BiologyAndMedicine57 (1984), 777-785

[23] F, Michael R. Drug Use during Pregnancy. Merck Manual Home Health Handbook. 2007.

[24] Frisancho, A Roberto, Jorge Matos and Laura A. Bollettino. 'Role of Gynecological Age and Growth Maturity Status in Prenatal Fetal Maturation and Growth of Infants Born to Young Still-Growing Adolescent Mothers "Human Biology Vol. 56, No. 3 (September 1984), pp. 583-593. Accessed on May 17, 2015; 21.00.

[25] Gilbert W 2004, Birth outcomes in teenage pregnancies. J Matern Fetal Neonatal Med. 2004 November; 16 (5): 265-70.

[26] Guo Y, Shen H, Xiao P, et al. Genome-wide linkage scan for quantitative trait loci underlying variation in age at menarche.
J Clin Endocrinol Metab2006; 91: 1009-1014. [PubMed]

[27] Heller. 2009. Clinical Medical Assisting: A Professional, Smart Field Approach to the Workplace. Delmar: New York (USA)

[28] Holcomb J, Sheeder J, Scott S, Stevens-Simon C. When pregnant teenagers are under, average, or overweight? J Pediatr Adolesc Gynecol 2007; 20: S120.

[29] Hollingworth, DR, 1986. Impact of gynecologic age on outcomes of adolescent pregnancy. Source: In: McAnarney ER, ed. Premature adolescent pregnancy and parenthood. New York,

[30] Grune and Stratton, 1983.169-90. (Monographs in Neonatalogy). Institute of Medicine, 1990. Nutrition during Pregnancy; Weight Gain, Nutrient Supplements.

[31] Jensen and Moore. 1997. The effect of high altitude and other risk factors on birth weight: independent or interactive effects? American Journal of Public Health June 1997: Vol. 87, No. 6, pp. 1003-1007. doi: 10.2105 / AJPH.87.6.1003

[32] Johanis, et al, 2011. Relations Socioeconomic Levels with Chronic Energy Deficiency in Pregnant mothers in the Village of West Kombos districts Singkil Manado City. Research Report. Sam Ratulangi University.

[33] Kara, F, et al, 2005. Maternal height as a risk factor for Caesarean section. Journal Archives of Gynecology and Obstetrics Volume 271, Issue 4, pp. 336-337

[34] Teen Pregnancy causes of the Risk of Death, Tempointeraktif, Saturday, January 2nd, 2010 | Date accessed: 22 Feb 2015. at: $22: 33 \mathrm{pm}$

[35] Ministry of Health, R.I, 2010. Health Service Neonatal-Based Child Protection. Special Children's Health Directorate. 2010. 